\title{
Bone mineral density and fractures in older men with chronic obstructive pulmonary disease or asthma
}

\author{
T.-T. Dam • S. Harrison • H. A. Fink • J. Ramsdell • \\ E. Barrett-Connor • \\ for the Osteoporotic Fractures in Men (MrOS) Research Group
}

Received: 22 September 2008 / Accepted: 26 August 2009 / Published online: 9 October 2009

(C) The Author(s) 2009. This article is published with open access at Springerlink.com

\begin{abstract}
Summary In 5,541 community dwelling men, chronic obstructive pulmonary disease, or asthma was associated with lower bone mineral density (BMD) at the spine and total hip and an increased risk of vertebral and nonvertebral fractures independent of age, body mass index, and smoking. Men prescribed with corticosteroids had the lowest BMD.
\end{abstract}

\section{T.-T. Dam}

Department of Medicine, College of Physicians and Surgeons, Columbia University,

New York, New York, USA

\section{S. Harrison}

Research Institute, California Pacific Medical Center,

San Francisco, California, USA

H. A. Fink

Geriatric Research Education and Clinical Center and Center for Chronic Disease Outcomes Research, Veterans Affairs Medical Center, Department of Medicine, University of Minnesota,

Minneapolis, Minnesota, USA

J. Ramsdell

Department of Medicine, School of Medicine,

University of California San Diego,

La Jolla, California, USA

E. Barrett-Connor

Department of Family and Preventive Medicine,

School of Medicine, University of California San Diego,

La Jolla, California, USA

\section{T.-T. Dam $(\bowtie)$}

Columbia University, College of Physicians and Surgeons, 5141 Broadway,

New York, New York 10035, USA

e-mail: td2265@columbia.edu.edu
Introduction It is unclear whether chronic obstructive pulmonary disease (COPD) is independently associated with BMD and fractures.

Methods In 5,541 men from the Osteoporotic Fractures in Men Study, history of COPD or asthma, current treatment with corticosteroids, BMD, bone loss after 4.5 years and fractures were ascertained.

Results Seven hundred fourteen (13\%) men reported COPD or asthma, of which 103 were prescribed an oral steroid and 177 an inhaled steroid. Independent of confounders, men prescribed corticosteroids for COPD or asthma had the lowest BMD and a 2-fold increased risk of vertebral osteoporosis compared to men with no history of COPD or asthma (OR 2.13, 95\% CI (confidence interval) $1.15-3.93$ oral steroids; OR 2.05 , 95\% CI 1.27 3.31 inhaled steroids). During follow-up, BMD increased at the spine, but there was no difference in bone loss at the hip. However, men with COPD or asthma had a 2.6- and 1.4-fold increased risk of vertebral and nonvertebral fractures, respectively.

Conclusion Chronic obstructive pulmonary disease or asthma was associated with lower BMD at the spine and hip and increased risk of vertebral and nonvertebral fractures independent of age, clinic site, BMI, and smoking. A history of COPD or asthma may be a useful clinical risk factor to identify patients with osteoporosis.

Keywords Bone loss · Bone mineral density - Elderly · Fractures $\cdot$ Pulmonary disease

\section{Introduction}

The National Heart Lung Blood Institute reports that an estimated 16 million adults are diagnosed with chronic obstructive pulmonary disease (COPD). Mainly caused by 
cigarette smoking, COPD was the fourth leading cause of death in older adults in 2004 [1]. By 2020, COPD is projected to be the third leading cause of death for both men and women. Among the comorbidities associated with COPD, osteoporosis is believed to affect $36 \%$ to $60 \%$ of patients with chronic lung disease [2-4]. The prevalence of osteoporosis and the risk of fractures increase with worsening airflow obstruction.

The relationship between obstructive pulmonary disease and osteoporosis is complicated. Both osteoporosis and COPD share some common risk factors. It is unclear whether the associations between COPD or asthma and osteoporosis is independently related to poor pulmonary function or to the effects of related attributes such as smoking, corticosteroids, low body weight, poor nutrition, and physical inactivity. The objective of the present study is to evaluate whether a history of COPD or asthma is an independent risk factor for low bone mineral density, bone loss, and fractures in older men.

\section{Methods}

\section{Participants}

From March 2000 to April 2002, the Osteoporotic Fractures in Men Study (MrOS) recruited 5,995 ambulatory community dwelling men aged 65 years or older at six clinical centers in the United States (Birmingham, Alabama; Minneapolis, Minnesota; Palo Alto, California; Monongahela Valley near Pittsburgh, Pennsylvania; Portland, Oregon; and San Diego, California). Men without bilateral hip replacements who were able to ambulate without the assistance of another person and were able to provide informed consent were recruited. Further details of the MrOS cohort, protocol, and recruitment have been published $[5,6]$. The institutional review boards at all participating centers approved the study protocol.

Of 5,995 men enrolled in MrOS, 454 were excluded from all analyses either due to missing baseline bone density measurements $(N=10)$, missing baseline medication inventory forms $(N=343)$, or baseline use of osteoporosis medications $(N=101)$, leaving 5,541 men for the crosssectional analyses. Of these men, 4,147 (75\%) returned for the second clinic visit and had repeated BMD measurements between December 2003 and April 2006, an average of 4.5 years later (range 3.5-5.9 years). These men comprised the participants in the longitudinal analyses. Among the men who were not included in the longitudinal analyses, 34 attended visit 2 but did not have repeat BMD measurements, 657 returned only the mailed questionnaire, 517 had died, 106 refused, and 80 left the cohort for various reasons, including poor health, participants moving away, being too busy, or loss of interest.

\section{Covariates}

At baseline, all participants completed a self-administered questionnaire, which included age, race/ethnicity, education level, marital status, personal medical history, and selfreported health and smoking history. Subjects were asked "Have you smoked at least 100 cigarettes (five packs) in your entire life?" Participants who answered "yes" were then asked the average number of cigarettes smoked per day and the number of years. The number of smoking packs per year was calculated and used for these analyses. The physical activity scale for the elderly (PASE) was used to assess physical activity level [7]. Participants were asked to bring in all prescription medications used within the last 30 days. All prescription medications were recorded in an electronic medications inventory database (San Francisco Coordinating Center, San Francisco, California, USA). Each medication was matched to its ingredient(s) based on the Iowa Drug Information Service (IDIS) Drug Vocabulary (College of Pharmacy, University of Iowa, Iowa City, Iowa, USA). Medications related to COPD or asthma were adjudicated and categorized as: (1) oral corticosteroids; (2) inhaled corticosteroids; (3) beta agonists/anticholinergics; and (4) other, which included mast cell stabilizers and leukotriene inhibitors. Height $(\mathrm{cm})$ was measured on Harpenden stadiometers, and weight $(\mathrm{kg})$ was measured on standard balance beam or digital scales using standard protocols. Body mass index (BMI) was calculated as weight divided by height $\left(\mathrm{kg} / \mathrm{m}^{2}\right)$.

\section{Ascertainment of pulmonary disease}

At the baseline visit, all participants were asked, "Has a doctor or other healthcare provider ever told you that you had or have chronic obstructive lung disease, chronic bronchitis, asthma, or chronic COPD?" If "yes," participants were asked, "Are you currently being treated for this condition by a doctor?" Participants were categorized based on their response to these two questions and by review of the medication inventory form. There were 4,827 men who did not report a history of COPD or asthma and were not prescribed any medications indicated for COPD or asthma. Of the 714 men who were identified as having COPD or asthma, 434 were not prescribed corticosteroids, 103 were prescribed an oral steroid, and 177 were prescribed inhaled corticosteroid. There were 16 men who were prescribed both an oral and inhaled corticosteroid, and they were grouped with the men who were taking oral steroids only. Duration of lung disease or corticosteroid treatment was not obtained. 
Bone mineral density

Bone mineral density was measured at the lumbar spine, total hip, and hip subregions using dual energy X-ray absorptiometry (DXA; QDR 4500W, Hologic, Inc., Waltham, Massachusetts, USA). Lumbar spine BMD for each subject was measured in the anterior-posterior projection and calculated as the mean of the BMD from the first through fourth lumbar vertebrae. All measurements of hip DXA BMD were made on the right hip, unless, the subject reported a right hip replacement or metal objects in the right leg in which case the left hip was measured. Repeat BMD were measured using the same DXA machines and methodology employed at visit 1 . The percent BMD change was determined by subtracting $\mathrm{BMD}$ at the baseline from BMD at the follow-up visit divided by baseline BMD and was expressed as an annualized percentage of the baseline value (percent/ year).

A central quality control lab, certification of DXA operators, and standardized procedures for scanning were used to insure reproducibility of DXA measurements. At baseline, a set of spine, hip, and linearity phantoms were circulated and measured at the six clinical sites. The variability across clinics was within acceptable limits, and cross calibration correction factors were not required. To adjust for interclinic differences, statistical models include indicator variable for the individual scanners. Each clinic scanned a spine and hip phantom throughout the study to monitor longitudinal changes, and correction factors were applied to participant data as appropriate. The precision of DXA scans of the spine and hip is $1-$ $2 \%$ [8].

Using normative data for young adult white males, BMD was categorized as normal, low bone mineral density, or osteoporosis, as defined by the World Health Organization $[9,10]$. To calculate hip and femoral neck T-scores, mean, and SD reference values from NHANES III were used [11]. For the spine T-scores, mean and SD reference values from the Hologic database were used. Participants with a T-score $\leq-2.5 \mathrm{SD}$ were categorized as having osteoporosis.

\section{Fractures}

After the baseline examination, participants were contacted about fractures every 4 months by postcard or telephone. The response rate to these questionnaires exceeded $99 \%$ in surviving men. Vertebral fractures were diagnosed clinically. Fractures were adjudicated centrally by physician review of medical records and X-ray reports. Unconfirmed and pathologic fractures were not included in the analyses. The mean follow-up time for incident fractures was 6.1 years.
Statistical analysis

Participant baseline characteristics were compared by COPD or asthma status using chi-square tests for categorical variables and analysis of variance for continuous variables. Least squared means linear regression models were used to examine the association between COPD or asthma status and BMD; cross-sectional results were expressed as mean BMD with corresponding 95\% confidence intervals (CI) and longitudinal results were expressed as mean annualized percent BMD change with corresponding 95\% CI. Logistic regression was used to assess the association between COPD or asthma status and osteoporosis risk; Cox proportional hazards models were used to assess the association between COPD or asthma status and fracture outcomes. Results were expressed as odds ratios and hazard ratios, respectively, with corresponding 95\% CI. To control for confounding by corticosteroid use, COPD or asthma was stratified by oral or inhaled corticosteroid use. Therefore, the predictor variable was categorized into four groups: (1) No COPD or asthma; (2) COPD or asthma, no steroids; (3) COPD or asthma, oral steroids; and (4) COPD or asthma, inhaled steroids. Known or suspected confounders of the relationship between pulmonary disease and BMD including age, BMI, ethnicity, smoking (packs per year), calcium or vitamin D supplement use, clinic site, hypertension, coronary artery disease, diabetes mellitus, stroke, self-reported health status, physical activity level, and alcohol were examined as potential covariates. Covariates were added to the multivariate models if the $p$ value was $<0.10$ in age-adjusted analysis. Model 1 demonstrates the parsimonious model adjusting for age, BMI, clinic, and smoking; Model 2 is adjusted for all possible confounders. All analyses were performed using SAS software, version 9.1 (SAS Institute, Cary, North Carolina, USA).

\section{Results}

Participant characteristics

Of the 5,541 MrOS participants, 714 (13\%) men were categorized as having COPD or asthma, of whom 280 were currently prescribed an inhaled and/or oral corticosteroid. Of the 280 men, 177 (63\%) were prescribed inhaled corticosteroid, 87 (31\%) were prescribed oral corticosteroid, and $16(6 \%)$ were prescribed both inhaled and oral corticosteroid. Of these 280 men, 165 (59\%) were also prescribed other COPD or asthma medications like a beta agonist, anticholinergic, mast cell stabilizer, and/or leucotriene inhibitors. For the other 434 men categorized as COPD or asthma, not on steroids, 108 (25\%) were 
prescribed a beta agonist, anticholinergic, mast cell stablizer, and/or leucotriene inhibitors.

Participant characteristics are presented in Table 1. Compared to men without COPD or asthma, men with COPD or asthma were older, less physically active, and reported poorer health status with more medical conditions, including hypertension, coronary artery disease, and stroke. Men who were taking oral steroids for COPD or asthma were older, less physically active, reported poorer health, and had more strokes and coronary artery disease. These men also had the heaviest smoking history, although, only $3 \%$ were currently smoking.

Oral corticosteroid use, smoking, decreased physical activity, self-reported fair/poor/very poor health, a history of stroke, and a history of coronary artery disease were independently associated with COPD or asthma in ageadjusted logistic regression models. Men who were prescribed oral corticosteroids were almost four times more likely to report a physician diagnosis of COPD or asthma (OR 3.88 (95\% CI 2.66-5.64)).

\section{Association of COPD or asthma with BMD}

In models adjusting for age, clinic site, BMI, and smoking, men with COPD or asthma had lower BMD at total hip, femoral neck, and spine compared to men who did not have COPD or asthma. Men who were taking oral or inhaled corticosteroids had lower BMD at the spine and hip, a difference between 0.02 to $0.05 \mathrm{~g} / \mathrm{cm}^{2}$ (Table 2). Adjustment for self-reported health, alcohol, calcium supplement, physical activity, coronary artery disease, stroke, and diabetes did not change the results.

Men with COPD or asthma not prescribed corticosteroids did not have an increased risk of osteoporosis at the hip, femoral neck, or spine after adjusting for confounders. However, men prescribed oral or inhaled corticosteroids had a 2-fold increased odds of osteoporosis at the spine in age-adjusted models (OR 2.13, 95\% CI 1.15-3.93 for oral steroids; OR 2.05, 95\% CI 1.27-3.31 for inhaled steroids). Additional adjustment for confounders attenuated the results, but oral steroid users still had a $91 \%$ increased risk of osteoporosis at the spine (OR 1.91, 95\% CI 1.02-3.58), and inhaled steroid user had a $71 \%$ increased risk of osteoporosis at the spine (OR 1.71, 95\% CI 1.04-2.81). Osteoporosis risk at the total hip and femoral neck were not statistically significant after multivariate adjustment (Table 3 ).

Association of COPD or asthma with bone loss

After 4.6 years of follow-up, there was no difference in the annual rate of bone loss at the total hip or femoral neck between men with or without COPD or asthma. However, spine BMD increased in all men. This is likely due to increased osteophyte formation from osteoarthritis (Table 4).

Association of COPD or asthma with incident fractures

Men with COPD or asthma had a 3-fold increased risk for incident clinical vertebral fractures compared to men who did not have COPD or asthma (OR 3.17, 95\% CI 1.935.20). The magnitude of the association with vertebral fractures decreased slightly after adjusting for confounders (OR 2.64, 95\% CI 1.57-4.44). In the group of men with COPD or asthma, taking inhaled corticosteroids, the risk for incident vertebral fractures was elevated almost 2-fold (OR $1.86,95 \%$ CI $0.80-4.32$; Table 5). This, however, did not meet statistical significance.

Men with COPD or asthma did not have an increased risk of hip fractures. Although men with COPD or asthma had a $12 \%$ increased risk of hip fractures (OR 1.12, 95\% CI $0.55,2.26)$, the OR included one and did not meet statistical significance. In men using oral or inhaled steroids for COPD or asthma, the results were similar.

Finally, men with COPD or asthma had a $42 \%$ increased risk of incident nonvertebral fractures (OR 1.42, 95\% CI 1.03-1.96). Men taking oral or inhaled steroids, however, did not have an increased risk of incident nonvertebral fractures.

\section{Discussion}

In this cohort of community dwelling older men, COPD or asthma was associated with lower BMD at the total spine, total hip, and femoral neck, but was not associated with increased bone loss 4.5 years later. However, men with COPD or asthma had a 2.6-fold increased risk of clinical vertebral fractures and a 1.4-fold increased risk of nonvertebral fractures approximately 6 years later. Additionally, men who were prescribed with inhaled or oral corticosteroids for COPD or asthma had lower BMD at all three sites and nearly a 2-fold increased risk of osteoporosis at the spine.

Previously published clinic-based studies suggest that $30-50 \%$ of all pulmonary disease patients (including subjects with COPD, cystic fibrosis, idiopathic pulmonary fibrosis, and those waiting on the transplant list) have osteoporosis at the spine or femoral neck [2, 4]. In another study, patients with chronic lung disease were found to have a 5-fold increased risk of hip or spine osteoporosis compared to controls; the risk increased to 9-fold if taking steroids [3]. Three cross-sectional observational studies have described an independent association between osteoporosis with poor pulmonary function (measured as forced 
Table 1 Baseline characteristics for men in the osteoporotic fractures in men study (MrOS) by chronic obstructive pulmonary disease or asthma status

\begin{tabular}{|c|c|c|c|c|c|}
\hline & $\begin{array}{l}\text { No COPD } \\
\text { or asthma } \\
(N=4827)\end{array}$ & $\begin{array}{l}\text { COPD or asthma, } \\
\text { no steroids } \\
(N=434)\end{array}$ & $\begin{array}{l}\text { COPD or asthma, } \\
\text { oral steroids } \\
(N=103)\end{array}$ & $\begin{array}{l}\text { COPD or asthma, } \\
\text { inhaled steroids } \\
(N=177)\end{array}$ & $p$ value \\
\hline Age (years) \pm SD & $73.5 \pm 5.9$ & $74.1 \pm 5.9$ & $74.3 \pm 5.6$ & $74.7 \pm 5.5$ & 0.002 \\
\hline \multicolumn{6}{|l|}{ Race (\%) } \\
\hline White & 89.0 & 91.0 & 87.4 & 87.0 & \multirow[t]{5}{*}{0.11} \\
\hline African-American & 4.1 & 5.3 & 7.8 & 4.5 & \\
\hline Asian & 3.5 & 0.9 & 1.9 & 4.0 & \\
\hline Hispanic & 2.2 & 1.4 & 1.9 & 4.0 & \\
\hline Other & 1.2 & 1.4 & 1.0 & 0.5 & \\
\hline $\mathrm{BMI}(\mathrm{kg} / \mathrm{m} 2) \pm \mathrm{SD}$ & $27.4 \pm 3.8$ & $27.7 \pm 4.3$ & $27.2 \pm 3.6$ & $26.9 \pm 4.1$ & 0.17 \\
\hline \multicolumn{6}{|l|}{ Smoking (\%) } \\
\hline Never & 39.2 & 25.6 & 32.0 & 24.9 & \multirow[t]{3}{*}{$<0.0001$} \\
\hline Past & 57.5 & 69.6 & 65.1 & 71.8 & \\
\hline Current & 3.3 & 4.8 & 2.9 & 3.4 & \\
\hline \multicolumn{6}{|l|}{ Number of packs per year (\%) } \\
\hline 0 & 39.5 & 25.8 & 32.0 & 24.9 & \multirow[t]{4}{*}{$<0.0001$} \\
\hline$>0-7$ & 12.8 & 8.3 & 14.6 & 11.3 & \\
\hline$>7-29$ & 25.3 & 23.0 & 21.4 & 24.3 & \\
\hline$>29$ & 22.4 & 42.9 & 32.0 & 39.6 & \\
\hline \multicolumn{6}{|l|}{ Alcohol drinks per week $(\%)$} \\
\hline 0 & 35.1 & 39.4 & 36.9 & 39.6 & \multirow[t]{3}{*}{0.58} \\
\hline $1-7$ & 47.1 & 44.4 & 46.6 & 45.2 & \\
\hline$>7$ & 17.8 & 16.2 & 16.5 & 15.3 & \\
\hline Physical activity $^{\mathrm{a}} \pm \mathrm{SD}$ & $148.3 \pm 67.9$ & $137.6 \pm 71.6$ & $128.4 \pm 77.4$ & $132.4 \pm 63.4$ & $<0.0001$ \\
\hline \multicolumn{6}{|l|}{ Self-reported health status (\%) } \\
\hline Excellent/good & 87.8 & 72.8 & 70.9 & 70.1 & \multirow[t]{2}{*}{$<0.0001$} \\
\hline Fair/poor/very poor & 12.2 & 27.2 & 29.1 & 29.9 & \\
\hline \multicolumn{6}{|l|}{ Medical conditions $(\%)$} \\
\hline Coronary artery disease & 13.7 & 16.6 & 21.4 & 16.6 & 0.04 \\
\hline Diabetes mellitus & 10.5 & 13.8 & 13.6 & 10.2 & 0.14 \\
\hline HTN & 43.5 & 46.5 & 45.6 & 46.9 & 0.51 \\
\hline Stroke & 5.3 & 6.9 & 10.7 & 7.3 & 0.04 \\
\hline Inhaled corticosteroid $(\%)$ & - & - & 15.5 & 100.0 & NA \\
\hline Oral corticosteroid $(\%)$ & - & - & 100.0 & - & NA \\
\hline Beta agonist and/or anticholinergic (\%) & - & 21.7 & 17.5 & 80.2 & $<0.0001$ \\
\hline Mast cell stabilizers and/or leucotriene agonist (\%) & - & 5.5 & 5.8 & 19.2 & $<0.0001$ \\
\hline Vitamin D supplement (\%) & 59.1 & 56.7 & 59.8 & 63.1 & 0.53 \\
\hline Calcium supplement $(\%)$ & 65.1 & 63.4 & 68.6 & 69.9 & 0.42 \\
\hline BMD total spine $\left(\mathrm{g} / \mathrm{cm}^{2}\right)$ & $1.08 \pm 0.18$ & $1.05 \pm 0.19$ & $1.03 \pm 0.16$ & $1.03 \pm 0.20$ & $<0.0001$ \\
\hline BMD total hip $\left(\mathrm{g} / \mathrm{cm}^{2}\right)$ & $0.96 \pm 0.14$ & $0.94 \pm 0.14$ & $0.92 \pm 0.13$ & $0.93 \pm 0.15$ & $<0.0001$ \\
\hline BMD femoral neck $\left(\mathrm{g} / \mathrm{cm}^{2}\right)$ & $0.79 \pm 0.13$ & $0.77 \pm 0.13$ & $0.76 \pm 0.13$ & $0.76 \pm 0.14$ & $<0.0001$ \\
\hline
\end{tabular}

NA not available

${ }^{a}$ physical activity scale elderly (PASE) score

expiratory volume in 1 second, $\mathrm{FEV}_{1}$ ) [12-14]. In these studies, BMD decreased approximately $0.02 \mathrm{~g} / \mathrm{cm}^{2}$ for every $1 \mathrm{~L}$ per second decrease in $\mathrm{FEV}_{1}$ and had a 2.4 increased risk of osteoporosis. Fractures have been docu- mented in $29 \%$ of COPD and 25\% of cystic fibrosis patients [4]. Vestegaard and colleagues found that chronic lung diseases like COPD and emphysema were associated with a 1.2- to 1.3-fold higher risk of fractures [15]. Inhaled 
Table 2 Age-adjusted and multivariate-adjusted ${ }^{\mathrm{a}}$ mean $(95 \% \mathrm{CI})$ bone mineral density by COPD or asthma and steroid status

\begin{tabular}{|c|c|c|c|c|c|}
\hline & $\begin{array}{l}\text { No COPD or asthma } \\
(N=4,827)\end{array}$ & $\begin{array}{l}\text { COPD or asthma, } \\
\text { no steroids } \\
(N=434)\end{array}$ & $\begin{array}{l}\text { COPD or asthma, } \\
\text { oral steroids } \\
(N=103)\end{array}$ & $\begin{array}{l}\text { COPD or asthma, } \\
\text { inhaled steroids } \\
(N=177)\end{array}$ & $p$ trend \\
\hline \multicolumn{6}{|c|}{ Total spine $\left(\mathrm{g} / \mathrm{cm}^{2}\right)$} \\
\hline Age-adjusted & $1.08(1.07-1.08)$ & $1.05(1.04-1.07)^{*}$ & $1.02(1.00-1.06)^{*}$ & $1.02(1.00-1.05)^{*}$ & $<0.0001$ \\
\hline Model $1^{\mathrm{a}}$ & $1.08(1.07-1.08)$ & $1.05(1.03-1.07)^{*}$ & $1.03(0.99-1.06)^{*}$ & $1.03(1.00-1.06)^{*}$ & $<0.0001$ \\
\hline Model $2^{\mathrm{b}}$ & $1.08(1.07-1.08)$ & $1.05(1.04-1.07)^{*}$ & $1.03(0.99-1.06)^{*}$ & $1.03(1.01-1.06)^{*}$ & $<0.0001$ \\
\hline \multicolumn{6}{|l|}{ Total hip $\left(\mathrm{g} / \mathrm{cm}^{2}\right)$} \\
\hline Age-adjusted & $0.96(0.96-0.97)$ & $0.94(0.93-0.96)^{*}$ & $0.92(0.90-0.95)^{*}$ & $0.93(0.91-0.95)^{*}$ & $<0.0001$ \\
\hline Model $1^{\mathrm{a}}$ & $0.96(0.96-0.97)$ & $0.94(0.93-0.96)^{*}$ & $0.92(0.90-0.95)^{*}$ & $0.94(0.92-0.96)^{*}$ & 0.0001 \\
\hline Model $2^{\mathrm{b}}$ & $0.96(0.96-0.96)$ & $0.95(0.94-0.96)^{*}$ & $0.93(0.90-0.95)^{*}$ & $0.94(0.92-0.96)$ & 0.0019 \\
\hline \multicolumn{6}{|c|}{ Femoral neck $\left(\mathrm{g} / \mathrm{cm}^{2}\right)$} \\
\hline Age-adjusted & $0.79(0.78-0.79)$ & $0.77(0.76-0.79)^{*}$ & $0.77(0.74-0.79)$ & $0.76(0.74-0.78)^{*}$ & 0.0006 \\
\hline Model $1^{\mathrm{a}}$ & $0.79(0.78-0.79)$ & $0.77(0.76-0.79)^{*}$ & $0.77(0.75-0.79)$ & $0.77(0.75-0.79)$ & 0.004 \\
\hline Model $2^{\mathrm{b}}$ & $0.79(0.78-0.79)$ & $0.78(0.77-0.79)$ & $0.77(0.75-0.80)$ & $0.77(0.76-0.79)$ & 0.03 \\
\hline
\end{tabular}

${ }^{\text {a }}$ Adjusted for age, clinic, BMI, and smoking

${ }^{\mathrm{b}}$ Adjusted for age, clinic, BMI, smoking, self-reported health, alcohol (drinks per week), calcium, PASE score, coronary artery disease, stroke, and diabetes

${ }^{*} p$ value $<0.05$ compared to no COPD or asthma group

corticosteroids have also been associated with increased fracture risk $[16,17]$.

In this cohort, men with a history of COPD or asthma did not have increased annual rate of bone loss at the total hip or femoral neck, but did have a 2.6-fold increase in vertebral fractures independent of confounders. The ob- served associations are likely underestimated in that they were attenuated by the selective loss of older participants with lower BMD levels, more lung disease, and poorer physical function at baseline. Moreover, more men with COPD or asthma died or did not participate at visit 2 . Although, we would have expected an increased risk of

Table 3 Likelihood of osteoporosis by chronic lung disease status

\begin{tabular}{|c|c|c|c|c|}
\hline & $\begin{array}{l}\text { No COPD or asthma } \\
(N=4827)\end{array}$ & $\begin{array}{l}\text { COPD or asthma, } \\
\text { no steroids }(N=434)\end{array}$ & $\begin{array}{l}\text { COPD or asthma, } \\
\text { oral steroids }(N=103)\end{array}$ & $\begin{array}{l}\text { COPD or asthma, } \\
\text { inhaled steroids }(N=177)\end{array}$ \\
\hline \multicolumn{5}{|c|}{ Total spine $\left(\mathrm{g} / \mathrm{cm}^{2}\right)^{\mathrm{a}}$} \\
\hline Age-adjusted & 1.0 (referent) & $0.99(0.65-1.50)$ & $2.13(1.15-3.93)$ & $2.05(1.27-3.31)$ \\
\hline Model $1^{\mathrm{c}}$ & 1.0 (referent) & $0.99(0.65-1.52)$ & $2.11(1.14-3.92)$ & $1.93(1.19-3.15)$ \\
\hline Model $2^{\mathrm{d}}$ & 1.0 (referent) & $0.93(0.61-1.44)$ & $1.91(1.02-3.58)$ & $1.71(1.04-2.81)$ \\
\hline \multicolumn{5}{|c|}{ Total hip $\left(\mathrm{g} / \mathrm{cm}^{2}\right)^{\mathrm{b}}$} \\
\hline Age-adjusted & 1.0 (referent) & $1.41(0.69-2.85)$ & $2.69(0.96-7.58)$ & $1.86(0.74-4.67)$ \\
\hline Model $1^{\mathrm{c}}$ & 1.0 (referent) & $1.17(0.56-2.44)$ & $2.27(0.77-6.70)$ & $1.29(0.49-3.38)$ \\
\hline Model $2^{\text {d }}$ & 1.0 (referent) & $1.08(0.51-2.28)$ & $2.08(0.51-2.27)$ & $1.07(0.69-6.26)$ \\
\hline \multicolumn{5}{|c|}{ Femoral neck $\left(\mathrm{g} / \mathrm{cm}^{2}\right)^{\mathrm{b}}$} \\
\hline Age-adjusted & 1.0 (referent) & $1.59(1.07-2.37)$ & $1.79(0.85-3.75)$ & $1.36(0.72-2.56)$ \\
\hline Model $1^{\mathrm{c}}$ & 1.0 (referent) & $1.41(0.92-2.14)$ & $1.65(0.77-3.54)$ & $1.06(0.55-2.03)$ \\
\hline Model $2^{\mathrm{d}}$ & 1.0 (referent) & $1.29(0.84-1.99)$ & $1.32(0.59-2.97)$ & $0.95(0.49-1.83)$ \\
\hline
\end{tabular}

${ }^{\mathrm{a}} \underline{\text { Using normals for men (Hologic) }}$

${ }^{\mathrm{b}}$ Using normals for men (NHANES)

${ }^{\mathrm{c}}$ Adjusted for age, clinic, BMI, and smoking

${ }^{\mathrm{d}}$ Adjusted for age, clinic, BMI, smoking, self-reported health, alcohol (drinks per week), calcium, PASE score, coronary artery disease, stroke, and diabetes 
Table 4 Age-adjusted and multivariate-adjusted ${ }^{\mathrm{a}}$ mean $(95 \% \mathrm{CI})$ annualized percent change bone mineral density by COPD or asthma status

\begin{tabular}{|c|c|c|c|c|c|}
\hline & $\begin{array}{l}\text { No COPD or asthma } \\
(N=3654)\end{array}$ & $\begin{array}{l}\text { COPD or asthma, } \\
\text { no steroids } \\
(N=294)\end{array}$ & $\begin{array}{l}\text { COPD or asthma, } \\
\text { oral steroids } \\
(N=103)\end{array}$ & $\begin{array}{l}\text { COPD or asthma, } \\
\text { inhaled steroids } \\
(N=177)\end{array}$ & $p$ trend \\
\hline \multicolumn{6}{|c|}{ Total spine $\left(\mathrm{g} / \mathrm{cm}^{2}\right)$} \\
\hline Age-adjusted & $0.62(0.58,0.66)$ & $0.55(0.41,0.68)$ & $0.72(0.45,0.99)$ & $0.91(0.72,1.11)^{*}$ & 0.03 \\
\hline Model $1^{\text {a }}$ & $0.62(0.58,0.66)$ & $0.55(0.42,0.68)$ & $0.77(0.50,1.03)$ & $0.92(0.72,1.11)^{*}$ & 0.01 \\
\hline Model $2^{\mathrm{b}}$ & $0.62(0.58,0.66)$ & $0.57(0.44,0.70)$ & $0.73(0.46,1.00)$ & $0.91(0.72,1.11)^{*}$ & 0.02 \\
\hline \multicolumn{6}{|c|}{ Total hip $\left(\mathrm{g} / \mathrm{cm}^{2}\right)$} \\
\hline Age-adjusted & $-0.37(-0.39,-0.34)$ & $-0.45(-0.55,-0.35)$ & $-0.24(-0.45,-0.04)$ & $-0.31(-0.46,-0.16)$ & 0.69 \\
\hline Model $1^{\mathrm{a}}$ & $-0.37(-0.40,-0.34)$ & $-0.44(-0.53,-0.34)$ & $-0.21(-0.42,-0.01)$ & $-0.33(-0.48,-0.18)$ & 0.60 \\
\hline Model $2^{\mathrm{b}}$ & $-0.37(-0.40,-0.34)$ & $-0.41(-0.51,-0.31)$ & $-0.17(-0.38,-0.03)$ & $-0.31(-0.46,-0.16)$ & 0.28 \\
\hline \multicolumn{6}{|c|}{ Femoral neck $\left(\mathrm{g} / \mathrm{cm}^{2}\right)$} \\
\hline Age-adjusted & $-0.35(-0.38,-0.31)$ & $-0.30(-0.43,-0.17)$ & $-0.26(-0.53,-0.01)$ & $-0.33(-0.53,-0.14)$ & 0.53 \\
\hline Model $1^{\mathrm{a}}$ & $-0.35(-0.38,-0.31)$ & $-0.31(-0.44,-0.18)$ & $-0.28(-0.55,-0.01)$ & $-0.33(-0.52,-0.13)$ & 0.60 \\
\hline Model $2^{\mathrm{b}}$ & $-0.35(-0.39,-0.32)$ & $-0.27(-0.40,-0.14)$ & $-0.26(-0.53,-0.01)$ & $-0.31(-0.50,-0.11)$ & 0.30 \\
\hline
\end{tabular}

${ }^{\text {a }}$ Adjusted for age, clinic, BMI, and smoking

${ }^{\mathrm{b}}$ Adjusted for age, clinic, BMI, smoking, self-reported health, alcohol (drinks per week), calcium, PASE score, coronary artery disease, stroke, and diabetes

${ }^{*} p$ value $<0.05$ compared to no COPD or asthma group

vertebral and hip fractures in men taking inhaled or oral corticosteroids, the $p$ value was not statistically significant and was likely due to the small sample size of fractures.

Smoking is a well-known cause of chronic lung disease. Corticosteroids, commonly prescribed to patients with COPD or asthma, are known to reduce bone formation and increased bone resorption [18]. Lower body weight and decreased exercise capacity in COPD patients have been shown to decrease bone mineral content and lean body mass [19]. Decreased muscle strength from physical inactivity can also accelerate respiratory decline and negatively affect BMD. In this study, corticosteroids and

Table 5 Age-adjusted and multivariate-adjusted ${ }^{a}$ hazard rates for hip and spine and nonhip and nonspine fractures by COPD or asthma status

\begin{tabular}{lllll}
\hline & $\begin{array}{l}\text { No COPD or asthma, } \\
(N=4,827)\end{array}$ & $\begin{array}{l}\text { COPD or asthma, no } \\
\text { steroids }(N=434)\end{array}$ & $\begin{array}{l}\text { COPD or asthma, oral } \\
\text { steroids }(N=103)\end{array}$ & $\begin{array}{l}\text { COPD or asthma, inhaled } \\
\text { steroids }(N=177)\end{array}$ \\
\hline Clinical vertebral fractures & $N=74$ & $N=20$ & $N=2$ & $N=6$ \\
Age-adjusted & 1.0 (referent) & $3.17(1.93,5.20)$ & $1.39(0.34,5.67)$ & $2.11(0.92,4.85)$ \\
Model $1^{\text {a }}$ & 1.0 (referent) & $2.98(1.80,4.94)$ & $1.35(0.33,5.50)$ & $2.00(0.87,4.61)$ \\
Model 2 & 1.0 (referent) & $2.64(1.57,4.44)$ & $1.14(0.28,4.71)$ & $1.86(0.80,4.32)$ \\
Hip fractures & $N=88$ & $N=11$ & $N=2$ & $N=5$ \\
Age-adjusted & 1.0 (referent) & $1.44(0.77,2.70)$ & $1.19(0.29,4.82)$ & $1.43(0.58,3.52)$ \\
Model $1^{\text {a }}$ & 1.0 (referent) & $1.30(0.68,2.45)$ & $1.14(0.28,4.63)$ & $1.41(0.57,3.48)$ \\
Model 2 & 1.0 (referent) & $1.09(0.56,2.14)$ & $0.92(0.22,3.77)$ & $1.24(0.50,3.09)$ \\
Clinical nonvertebral, nonhip fractures & $N=359$ & $N=43$ & $N=4$ & $N=17$ \\
Age-adjusted & 1.0 (referent) & $1.40(1.02,1.91)$ & $0.56(0.21,1.49)$ & $1.30(0.80,2.11)$ \\
Model $1^{\text {a }}$ & 1.0 (referent) & $1.42(1.03,1.96)$ & $0.56(0.21,1.51)$ & $1.29(0.79,2.11)$ \\
Model 2 & 1.0 (referent) & $1.42(1.03,1.96)$ & $0.55(0.21,1.48)$ & $1.28(0.78,2.09)$
\end{tabular}

Bolded cells have $p$ values $<0.05$

${ }^{\text {a }}$ Adjusted for age, clinic, BMI, and smoking

${ }^{\mathrm{b}}$ Adjusted for age, clinic, BMI, smoking, self-reported health, alcohol (drinks per week), calcium, PASE score, coronary artery disease, stroke, and diabetes 
smoking appeared to mediate most of the observed associations and additional adjustments for possible confounders did not attenuate the observed results.

We hypothesized that corticosteroids, smoking, physical inactivity, low body weight, and/or malnutrition would have explained the lower BMD and higher rates of osteoporosis in patients with obstructive pulmonary disease. It is unclear why men with COPD or asthma would have lower BMD at the total spine and hip independent of these confounders. Increased levels of systemic inflammation may be a potential mechanism to explain how pulmonary disease may affect bone. Several studies have demonstrated that individuals with chronic airflow limitation have significantly elevated levels of C-reactive protein, fibrinogen, leucocytes, and tumor necrosis factor alpha [20]. Low grade systemic inflammation persists even in nonsmoking subjects with chronic airflow limitation, suggesting that smoking cessation does not eliminate ongoing inflammation and that inflammation is not due to tobacco alone [21]. Another potential mechanism could be due to hypercapnia, which has been associated with increased bone resorption. Dimai and colleagues showed that lower arterial $\mathrm{pH}$ and higher arterial carbon dioxide levels were correlated with lower BMD in COPD patients [22]. Finally, hormonal levels may be another mechanism. Hormone replacement therapy and increased circulating estrogen levels had a protective effect on pulmonary function in pre- and postmenopausal women [23]. Further studies to examine whether inflammation, hypercapnia, or sex hormones mediates the relationship between pulmonary disease and BMD are needed.

This study had several limitations. First, ascertainment of obstructive pulmonary disease was by self-report, and pulmonary function was not measured by spirometry. Therefore, we were unable to make a specific pulmonary diagnosis (i.e., chronic bronchitis, emphysema, and asthma). Duration of pulmonary disease and duration of corticosteroid treatment was unknown; therefore, any dose-response relationship with treatment could not be examined. These findings apply primarily to older Caucasian men and may not be generalized to other populations. Finally, the relative independent contribution of COPD or asthma to BMD may be small. However, when this risk factor is examined in combination with other concomitant osteoporosis risk factors such as glucocorticoid use, weight loss, physical activity, vitamin D deficiency, the increased risk of osteoporosis, and fracture may be large and clinically relevant.

Despite these limitations, this study had many strengths including the high rates of follow-up, careful standardized collection of detailed covariate data, BMD collection following rigorous quality control measures, and careful adjudication of fracture outcomes. Medication use was validated in the clinic and accurately recorded on the electronic medication inventory form. The careful adjudication of medications prescribed for COPD or asthma limits misclassification bias. Additionally, the large sample of 5,541 healthy men selected from the community without any specific pulmonary complaints reduces the potential for volunteer bias, which is often a problem with clinic-based populations. This enhances generalizability and comparison with other cohorts.

The WHO estimates that 3 million people died of COPD in 2005 and another 80 million people have moderate to severe COPD. Chronic obstructive pulmonary disease is projected to become the third leading cause of death worldwide and is a major public health concern. Therefore, clinicians may find that a history of COPD or asthma with or without use of corticosteroids may be a useful risk factor to identify patients who may benefit from early diagnostic and preventive strategies for osteoporosis.

Funding The Osteoporotic Fractures in Men (MROS) Study is supported by National Institutes of Health funding. The following institutes provided support: the National Institute of Arthritis and Musculoskeletal and Skin Diseases (NIAMS), the National Institute on Aging (NIA), the National Cancer for Research Resources (NCRR), and the NIH Roadmap for Medical Research under the following grant numbers-U01 AR45580, U01 AR45614, U01 AR45632, U01 AR45647, U01 AR45654, U01 AR45583, U01 AG18197, UO1AG027810, and UL1 RR024140. The funding institutes had no role in the collection, analysis or interpretation of the data, or in the decision to submit the paper for publication.

Conflicts of interest T.-T. Dam, S. Harrison, H. Fink, and J. Ramsdell had no financial support while E. Barrett-Connor had consulting contracts and research support from Eli Lilly and Company and Merck and Company.

Open Access This article is distributed under the terms of the Creative Commons Attribution Noncommercial License which permits any noncommercial use, distribution, and reproduction in any medium, provided the original author(s) and source are credited.

\section{References}

1. Minino AM, Heron MP, Smith BL (2006) Deaths: preliminary data for 2004. Natl Vital Stat Rep 54:1-49

2. Incalzi RA, Caradonna P, Ranieri P, Basso S, Fuso L, Pagano F, Ciappi G, Pistelli R (2000) Correlates of osteoporosis in chronic obstructive pulmonary disease. Respir Med 94:10791084

3. Iqbal F, Michaelson J, Thaler L, Rubin J, Roman J, Nanes MS (1999) Declining bone mass in men with chronic pulmonary disease: contribution of glucocorticoid treatment, body mass index, and gonadal function. Chest 116:1616-1624

4. Shane E, Silverberg SJ, Donovan D, Papadopoulos A, Staron RB, Addesso V, Jorgesen B, McGregor C, Schulman L (1996) 
Osteoporosis in lung transplantation candidates with end-stage pulmonary disease. Am J Med 101:262-269

5. Blank JB, Cawthon PM, Carrion-Petersen ML, Harper L, Johnson JP, Mitson E, Delay RR (2005) Overview of recruitment for the osteoporotic fractures in men study (MrOS). Contemp Clin Trials 26:557-568

6. Orwoll E, Blank JB, Barrett-Connor E, Cauley J, Cummings S, Ensrud K, Lewis C, Cawthon PM, Marcus R, Marshall LM, McGowan J, Phipps K, Sherman S, Stefanick ML, Stone K (2005) Design and baseline characteristics of the osteoporotic fractures in men (MrOS) study - a large observational study of the determinants of fracture in older men. Contemp Clin Trials 26:569-585

7. Washburn RA, Ficker JL (1999) Physical Activity Scale for the Elderly (PASE): the relationship with activity measured by a portable accelerometer. J Sports Med Phys Fitness 39:336-340

8. Cummings SR, Bates D, Black DM (2002) Clinical use of bone densitometry: scientific review. JAMA 288:1889-1897

9. Kanis JA (1994) Assessment of fracture risk and its application to screening for postmenopausal osteoporosis: synopsis of a WHO report. WHO Study Group. Osteoporos Int 4:368-381

10. Report of a WHO Study Group (1994) Assessment of fracture risk and its application to screening for postmenopausal osteoporosis. World Health Organ Tech Rep Ser 843:1-129

11. Looker AC, Johnston CC Jr, Wahner HW, Dunn WL, Calvo MS, Harris TB, Heyse SP, Lindsay RL (1995) Prevalence of low femoral bone density in older U.S. women from NHANES III. J Bone Miner Res 10:796-802

12. Sin DD, Man JP, Man SF (2003) The risk of osteoporosis in Caucasian men and women with obstructive airways disease. Am J Med 114:10-14

13. Lekamwasam S, Trivedi DP, Khaw KT (2002) An association between respiratory function and bone mineral density in women from the general community: a cross sectional study. Osteoporos Int 13:710-715
14. Lekamwasam S, Trivedi DP, Khaw KT (2005) An association between respiratory function and hip bone mineral density in older men: a cross-sectional study. Osteoporos Int 16:204-207

15. Vestergaard P, Rejnmark L, Mosekilde L (2007) Fracture risk in patients with chronic lung diseases treated with bronchodilator drugs and inhaled and oral corticosteroids. Chest 132:1599-1607

16. Pujades-Rodriguez M, Smith CJ, Hubbard RB (2007) Inhaled corticosteroids and the risk of fracture in chronic obstructive pulmonary disease. QJM 100:509-517

17. Hubbard R, Tattersfield A, Smith C, West J, Smeeth L, Fletcher A (2006) Use of inhaled corticosteroids and the risk of fracture. Chest 130:1082-1088

18. Lukert BP, Raisz LG (1994) Glucocorticoid-induced osteoporosis. Rheum Dis Clin North Am 20:629-650

19. Yoshikawa M, Kobayashi A, Yamamoto C, Fu A, Takenaka H, Ikuno M, Yoneda T, Narita N, Nezu K, Kitamura S (1997) Exercise performance and body composition in patients with chronic obstructive pulmonary disease. Nihon Kyobu Shikkan Gakkai Zasshi 35:518-523

20. Sin DD, Man SF (2006) Skeletal muscle weakness, reduced exercise tolerance, and COPD: is systemic inflammation the missing link? Thorax 61:1-3

21. Crook MA, Scott DA, Stapleton JA, Palmer RM, Wilson RF, Sutherland G (2000) Circulating concentrations of C-reactive protein and total sialic acid in tobacco smokers remain unchanged following one year of validated smoking cessation. Eur J Clin Invest 30:861-865

22. Dimai HP, Domej W, Leb G, Lau KH (2001) Bone loss in patients with untreated chronic obstructive pulmonary disease is mediated by an increase in bone resorption associated with hypercapnia. J Bone Miner Res 16:2132-2141

23. Carlson CL, Cushman M, Enright PL, Cauley JA, Newman AB (2001) Hormone replacement therapy is associated with higher FEV1 in elderly women. Am J Respir Crit Care Med 163:423-428 